\title{
Human Lateralization among Monozygotic and Dizygotic Twins in Koya Town
}

\author{
Karim Jalal Karim \\ Depart. Medical Microbiology, Koya University \\ University Park, Daniel Mitterrand Boulevard, Koya KOY45 AB64, Kurdistan Region-Iraq \\ Tel: 964-750-492-5814Ｅ-mail: karim.jalal@koyauniversity.org \\ Saifadin Khder Mustafa \\ Depart. Medical Microbiology, Koya University \\ University Park, Daniel Mitterrand Boulevard, Koya KOY45 AB64, Kurdistan Region-Iraq \\ Tel: 964-750-753-9290Ｅ-mail: saifadin.khder@koyauniversity.org
}

Kewan Kamal Ahmad

Deputy Head of Biology Department

Faculty of Science \& Health, School of Science, Dept. of Biology, University Park

Daniel Mitterrand Boulevard, Koya KOY45 AB64, Kurdistan Region-Iraq

Tel: 964-750-112-3722Ｅ-mail: kewan.kamal@ koyauniversity.org

Received: December 15, 2014 Accepted: January 4, 2015

doi:10.5296/jbls.v6i1.6776 URL: http://dx.doi.org/10.5296/jbls.v6i1.6776

\begin{abstract}
At present, we do not understand how human handedness arose. Although much attention has been paid to several genetic theories, some studies involving twins have indicated that the influence of genetic and environmental factors on handedness may be minimal or nonexistent.

The incidence of left-handedness amongst males is higher than with females, according to a large body of research. People who are ambidextrous are more likely to start to write with their right hand, even when they are not forced to do this. The left hemisphere of the brain is also lateralized when compared to the right hemisphere and vice versa.
\end{abstract}

Our research examined handedness in dizygotic and identical monozygotic twins in Koya 
Town/ Erbil governorate. In 2014, we mailed a questionnaire to 100 twins aged between 18 and 50 to survey their handedness. The survey determined whether each subject was a monozygotic or dizygotic twin, and then questioned them about their handedness. We examined whether both twins had the same handedness or different handedness, and whether individual twins have a higher prevalence of left-handedness or right-handedness.

The results revealed that in $62 \%$ of cases, both monozygotic twins in a pair are right-handed. On the other hand, both dizygotic twins are right-handed only $54 \%$ of the time. Furthermore, dizygotic twins are more likely to have one left-handed and one right-handed twin when compared to monozygotic twins. We also found that the prevalence of right handedness in individual monozygotic twins regardless of the handedness of the other twin was $77 \%$, whereas the prevalence of left-handedness was only $21 \%$. The remaining $2 \%$ of monozygotic subjects were ambidextrous.

These results indicate that unique genetic and environmental factors may account for the majority of variance in that is observed in handedness, although the relationship between the brain, handedness, environmental effects and genetic effects is a complex one. This is a view that is corroborated by a number of recent neuroscientific and genetic studies that are examined in this article.

Keywords: Handedness, Laterality, Monozygote, Dizygote, Behaviour genetics

\section{Introduction}

Each hemisphere of the brain specializes in processing sensory information that is not processed in the other hemisphere (Forrester et al., 2014). This functional split, which is found in both invertebrates and vertebrates, is posited to provide an evolutionary advantage by increasing neural processing efficiency (Gu et al., 2013). Lateralization of cerebral function allows disparate processing tasks to be carried out in parallel in each hemisphere, decreasing wasteful duplication and eliminating the possibility of simultaneous conflicting results arising from the two hemispheres (Toga et al., 2003). Because of this, the right hemisphere of the brain controls the left side of the body and vice versa (Knecht et al., 2000). Furthermore, specializations in one hemisphere can give rise to physical effects on the opposite side of the body. Handedness is the most well-known example of this shared hemispheric and anatomical lateral bias in humans (Joseph and Hellige, 1993).

Although Galton is frequently credited with using twins to study the relative effects of genetics and environment, it was in fact Siemens who first use classical twin studies in 1924 to examine similarities in pairs of dizygotic (DZ) and monozygotic (MZ) twins (Steinman, 2006).

The process through which MZ twins are created provides a special opportunity to gain insights into human development (Amar and Klar, 1999). Since MZ twins both arise from a single fertilized ovum, they also share all of their genetic material (Pechnikova et al., 2014). However, notwithstanding this genetic commonality, MZ twins still demonstrate different phenotypes due to environmental influences, as well as due to different $\mathrm{X}$ chromosomes being deactivated in MZ female twins (Edwards et al., 2014). In addition, while MZ twins share a common generic heritage, they are not genetically identical (Pechnikova et al., 2014). 
Hundreds of genetic differences arise early in fetal development due to somatic mutations that result from copying errors. Studies in the past have explored epigenetic effects, genetic differences that result from chemical modification. However, no one has characterized the frequency of these types of mutations (Daily Mail, 2014).

On the other hand, DZ twins only share one half of their genes on average, since they arise from two distinct ova that are fertilized separately. By studying and comparing MZ and DZ twins, researchers can study the degree to which genetics contributes to specific phenotypes, provided that environmental effects are eliminated by studying twins that are raised together (Pechnikova et al., 2014). By comparing DZ and MZ twins, researchers can estimate the heritability of traits - the amount of variance that can be ascribed to genetic factors (Bell and Saffery, 2012).

One study has shown that consuming dairy products may increase the likelihood of DZ twins due to the presence of insulin-like growth factor (IGF). The study reported that vegetarian or omnivore mothers are five times as likely to have twins as vegan mothers, and observed that diets that include dairy products tend to stimulate the ovaries and increase the chances of twins, particularly in areas where cattle are given growth hormones (Oxford Health Review, 2014). In corroboration of this, the number of twins born in the United States increased 52\% between 1980 and 1997 (Steinman, 2006). This rise may be partially due to the increased use of fertility drugs such as Clomid, which give rise to twins more frequently than natural fertilization. However, the increase may also be partially attributable to the increased concentrations of growth hormones in our food supply.

Left-handedness is more commonly found in triplets $(7.1 \%)$ and twins $(8.1 \%)$ than in single births, while ambidextrous triplets $(6.4 \%)$ are more prevalent than ambidextrous twins $(3.4 \%)$ or singletons (3.5\%) (Vuoksimaa, et al., 2009; Orlebeke, et al., 1996). Other studies from the past two decades have affirmed earlier research that reported left-handedness was more prevalent in twins than in single births, and that left-handedness was also more common in males than females (Davis and Annett, 1994; Papadatou-Pastou et al., 2008).

Davis and Annette in particular found their results to be strong empirical evidence for the RS handedness theory, first proposed in 1978 by Annette and then revised in 1985. In this model, RS stands for "right shift", referring to one or more unidentified genes that increase the likelihood of right-handedness in humans. This theory holds that handedness arises entirely through chance, and that the split between left and right is normally 50/50 - as is found in most mammals. However, in humans, there is a hypothetical gene that shifts the distribution towards the right if it is present, whereas the distribution is not shifted and remains 50/50 if the gene is not present. This accounts for the predominance of right-handedness amongst humans. The theory assumes that the "right shift" mechanism operates through a single locus with two alleles ( $r s+$ and $\mathrm{rs}-$ ), and that homozygosity produces a stronger right shift than heterozygosity.

The higher prevalence of left-handedness in twins and males when compared to singletons and females can be explained by making the assumption that the rs + gene is expressed less in males and twins. On the other hand, a number of authors (Ocklenburg, et al., 2013) have 
suggested that handedness may be determined by a complex set of phenotype factors rather than by one gene. There is also strong evidence that the ontogeny of handedness may be determined to a certain degree by genetic factors (Reiss and Reiss, 1999).

This study examines handedness of MZ and DZ twins in Koya Town/Erbil Governorate, using an accurate questionnaire methodology.

\section{Materials \& Methods}

The samples that were studied were collected in Koya Town/Erbil Governorate, and included both genders - male and female. In total, the data set covered $50 \mathrm{DZ}$ and $50 \mathrm{MZ}$ twins. Twinhood was accurately established by the questionnaire that was distributed, as was the MZ or DZ nature of each twin pair surveyed.

Once candidate twins were identified in Koya town, a questionnaire was sent in 2014 to subjects who satisfied the twin pair selection criteria. The number of respondents and the data collection methodology are summarized in this article. Two questions were used to assess handedness: Do you use both hands equally, yes or no? Are you right-handed or left-handed?

\section{Result}

Responses from $50 \mathrm{MZ}$ and $50 \mathrm{DZ}$ twins of both genders from Koya town were assessed. Specifically, the responses with regard to hand preference were analyzed by type of twin (see Table 1 and Figure 1) and using a chi-square test.

Figure 1 shows that both twins shared right-handedness (R/R) more often in MZ pairs $(62 \%)$ than in DZ pairs (54\%), and the same applied for left-handedness (L/L) - 6\% for MZ twins and $4 \%$ for DZ twins. In contrast, more DZ pairs ( $42 \%$ ) were likely to have one right-handed and one left-handed twin (R/L) when compared to MZ pairs (28\%). Additionally, 4\% of MZ twins were ambidextrous (RL), whereas none of the DZ twins in the sample were.

When the handedness of individual twins is examined - without taking into account the handedness of the other twin - the overall rate of right-handedness (R) in MZ twins is $77 \%$, slightly higher than in DZ twins (75\%). The data also clearly showed left-handedness was more prevalent in DZ twins (25\%) than in MZ twins (2\%). $2 \%$ of MZ twins were ambidextrous, but there were no ambidextrous DZ twins $(0 \%)$.

Table 1. Handedness distribution in MZ and DZ twins

\begin{tabular}{|c|c|c|c|c|c|c|}
\hline \multirow{2}{*}{ Group } & \multicolumn{2}{|c|}{ MZ twins } & \multicolumn{2}{c|}{ DZ twins } & \multicolumn{2}{c|}{ MZ \& DZ twins } \\
\cline { 2 - 7 } & Number & $\%$ & Number & $\%$ & Number & $\%$ \\
\hline R R & 31 & 62 & 27 & 54 & 58 & 58 \\
\hline R L & 14 & 28 & 21 & 42 & 35 & 35 \\
\hline L L & 3 & 6 & 2 & 4 & 5 & 5 \\
\hline $\begin{array}{c}\text { RL R or } \\
\text { RL L }\end{array}$ & 2 & 4 & 0 & 0 & 2 & 2 \\
\hline Total & 50 & 100 & 50 & 100 & 100 & 100 \\
\hline
\end{tabular}


$\mathrm{R}=$ right-handed, $\mathrm{L}=$ left-handed, $\mathrm{RL}=$ ambidextrous, $\mathrm{MZ}=$ Monozygotic, $\mathrm{DZ}=$ Dizygotic

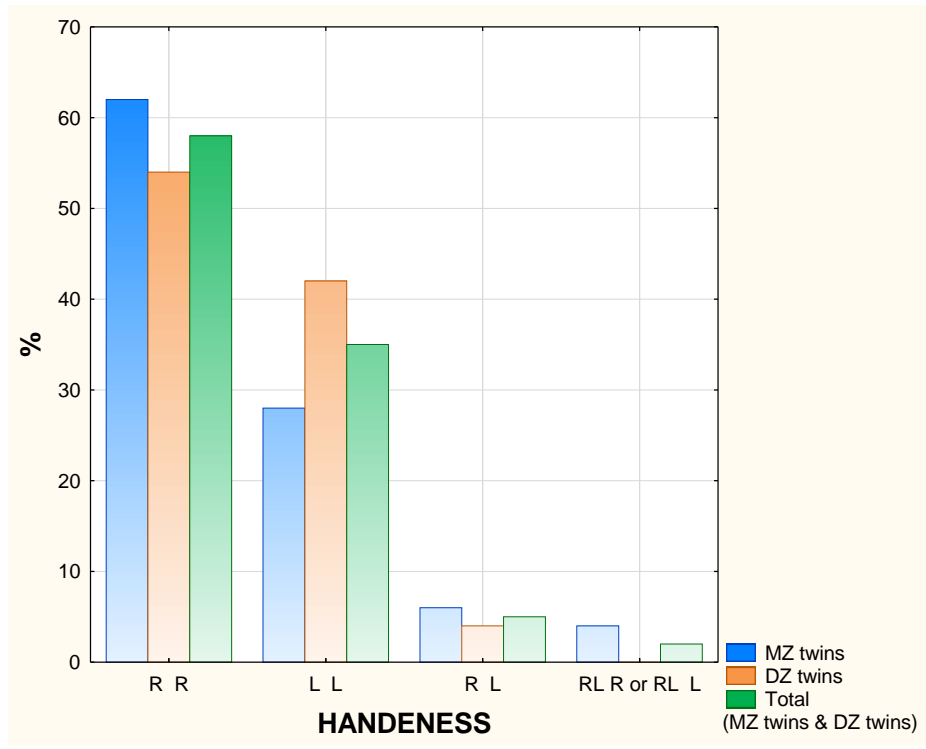

Figure 1. Handedness distribution in MZ and DZ twin pairs.

\section{Discussion}

In this study, a questionnaire was used to survey the distribution of handedness in MZ and DZ twins in Koya town. The questionnaire was used to determine twinship as well as whether the twin pair was MZ or DZ. The validity of the samples was measured using a chi-square test.

Handedness has been the subject of study for many years. Although several theories have been put forward to explain the origin of handedness, the determining factors behind human handedness are still not clearly understood (Vuoksimaa, et al., 2009). However, there is some data that suggests that handedness is determined prior to birth to some extent. Ultrasound studies have shown that human fetuses have a preference for moving their right hand by 10 weeks into gestation, and that they maintain this preference as late as 27 weeks (Vuoksimaa, et al., 2010).

Our sample showed that DZ twins were more likely to be left-handed (25\%) than were MZ ones (20\%). In fact, the results we obtained showed a slightly higher prevalence of left-handedness than in some major studies. However, the majority of studies have reported that left-handedness occurs approximately $24 \%$ of the time (Peters, 2006; Gilbert and Wysocki 1992), which is broadly in line with our results.

Right-handedness in individual MZ twins (77\%) is slightly greater than that in DZ twins (75\%). This demonstrates to us that right-handedness is more common in both types of zygosity than non-right-handedness.

Table 2 shows that $2 \%$ of MZ twins are ambidextrous, whereas none of the DZ twins $(0 \%)$ were. In the past, a number of studies have divided subjects into two groups right-handed and non-right handed, incorporating ambidextrous individuals into the non-right-handed group (Medland et al., 2003). Our results suggest that it is more appropriate to treat ambidexterity as 
a discrete trait when subjects identify themselves as ambidextrous, rather than classifying them along with left-handed subjects into a non-right-handed group. If this is the case, this goes against the view that ambidextrous people are more likely to write with their left hand in the absence of cultural pressure. In fairness, we assessed ambidexterity using a single question, and hence may not capture all of the nuances and complexity of ambidexterity. However we would that both individuals who are categorized as ambidextrous in our study were categorized this way because they could use both hands. Therefore, they could not be classified as left-handed or right-handed.

Two studies (Vuoksimaa, et al., 2010; Tran et al., 2014) have shown that the majority of humans are right-handed and that this is linked to lateralization in the brain. A minority are left-handed and a small number are ambidextrous - however, the prevalence of left-handedness may be different in different cultures.

Some previous studies of handedness in twins have not found any family-related effects, which may have resulted from the studies not having the power to recognize common genetic or environmental factors. Twins who are both left-handed are relatively uncommon as shown by our results and therefore very large groups of subjects are needed to ascertain any family-related influences. However, genetic mapping research has recently indicated that genetics may play a role in handedness (Francks et al., 2002).

Table 2. Number and percentage of RH, LH and ambidextrous individuals amongst MZ and DZ twins

\begin{tabular}{|l|c|c|}
\hline Twin & Number & Percentage $\%$ \\
\hline MZ twins & & \\
Right-handed & 77 & $77 \%$ \\
Left-handed & 21 & $21 \%$ \\
Ambidextrous & 2 & $2 \%$ \\
DZ twins & & \\
Right-handed & 75 & $75 \%$ \\
Left-handed & 25 & $25 \%$ \\
Ambidextrous & 0 & $0 \%$ \\
\hline
\end{tabular}

In dyslexics, handedness as measured by hand skills has been shown to be linked to a gene on chromosome 2p12, LRRTM1 (Francks et al., 2007). Some results have also been found in the general population that androgen receptor length was linked to the hand that people write with, as was chromosome 12q21-23 (Medland et al. 2005, Warren, Stern, Duggirala, Dyer, and Almasy, 2006). When handedness is evaluated using the Edinburgh Handedness Inventory, it has also been shown to have a chromosome 10q26 linkage (Van Agtmael et al., 2002).

These studies provide clear evidence that genes are involved in handedness, while indicating that handedness is most likely not determined by a single gene. However, while genes play a role, it appears that environmental effects also play a large part in handedness. In order to understand how human handedness comes about, we need to pursue a holistic approach that examines both genetic and environmental factors. 
At the moment, it is uncertain how the environment plays a role in determining the dominant brain hemisphere in handedness. One possible factor might be that the arms and by extension hemispheres have complementary functions during motor activities. The dominant hemisphere is better at processing visual feedback and trajectories, while the other hemisphere is better at controlling position and processing feedback from proprioception. These differences may well give rise to specialization in hand motor skills. Another possibility is that the motor cortex's asymmetry may be responsible for handedness; the motor cortex in the left hemisphere usually demonstrates greater connectivity (Goble and Brown, 2008).

Since we live in a society that has a strong bias towards the use of the right hand, this might promote greater use of the right hand for trajectory and the left hand for positional control. This could in turn mask the genetic potential for reversal of asymmetry in the motor cortex. However, in societies that have a more permissive attitude towards use of the left hand, one might expect a greater variation in handedness. Beyond genetic considerations, other effects such as lesions and hormonal influences may also play a role. Given that the variation of handedness in individuals can be explained by unique environmental effects, while there is also an overall bias towards right-handedness, it may be that asymmetry promotes use of the right hand, but that the right hemisphere works as a backup when needed. It would be useful to study whether differences in arm roles - trajectory/positional vs visual/proprioceptive - have an environmental or genetic basis by studying these phenomena in twins.

\section{Conclusion}

For more than a hundred years, studies of twins have played an essential role when it comes to understanding the nature of individual variation. In the last few decades, these types of studies have been vital when looking at complex traits and their genetic bases. The key advantage of twin studies is that they can separate environmental and genetic factors by comparing identical MZ twins to DZ twins that only share $50 \%$ of their genetic material on average.

In our study, we found that $62 \%$ of MZ twins shared the same handedness, whereas only $54 \%$ of DZ twins did so. Our data indicates that handedness and corresponding lateralization may be influenced by multiple genetic and epigenetic factors. In general, potential environmental influences on handedness may be divided into two groups. The first is external influences, such as climate, food and so on. The second is the internal environment within the womb.

In conclusion, we have shown that MZ twins are more likely to become right-handed, and that the variation in handedness can be explained by environmental and genetic effects.

\section{Reference}

Bell, J. B., \& Saffery, R. (2012) The value of twins in epigenetic epidemiology. International Journal of Epidemiology. 41, 140-150. http://dx.doi.org/10.1093/ije/dyr179

Forrester, G. S., Pegler, R., Thomas, M. S. C., \& Mareschal D. (2014) Handedness as a marker of cerebral lateralization in children with and without autism. Behavioural Brain Research. 268, 14-21. http://dx.doi.org/10.1016/j.bbr.2014.03.040

Gu, F., Zhang , C., Hu , A., \& Zhao, G. (2013) Left hemisphere lateralization for lexical and 
acoustic pitch processing in Cantonese speakers as revealed by mismatch negativity. NeuroImage. 83, 637-645. http://dx.doi.org/10.1016/j.neuroimage.2013.02.080

Toga, A. W., \& Thompson, P. M. (2003) Mapping brain asymmetry. Nature Reviews Neuroscience. 4, 37-48. http://dx.doi.org/10.1038/nrn1009

Knecht, S., Dräger, B., Deppe, M., Bobe, L., Lohmann, H., Flöel, A., Ringelstein, E. B., \& henningsen, H. (2000) Handedness and hemispheric language dominance in healthy humans. Brain. 123, 2512-2518. http://dx.doi.org/10.1093/brain/123.12.2512

Joseph, B., \& Hellige, J. B. (1993) Unity of Thought and Action: Varieties of Interaction Between the Left and Right Cerebral Hemispheres. Current Directions in Psychological Science. 2, 21-26. http://dx.doi.org/10.1111/1467-8721.ep10770559

Steinman, B. G. (2006) Mechanisms of twinning: VII. Effect of diet and heredity on the human twinning rate. J Reprod Med, 51(5), 405-410.

Amar J. S., \& Klar, A. J. S. (1999) Genetic models for handedness, brain lateralization, schizophrenia, and manic-depression. Schizophrenia Research. 39, 207-218. http://dx.doi.org/10.1016/S0920-9964(99)00075-4

Pechnikova, M., De Angelis, D., Gilbelli, D., Vecchio, V., Cameriere, R., Zeqiri, B., \& Cattaneo, C. (2014) Twins and the paradox of dental-age estimations: A caution for researchers and clinicians. Journal of Comparative Human Biology, 65(4). http://dx.doi.org/10.1016/j.jchb.2014.05.003

Edwards, J. H., Dent, T., \& Kahn, J. (1966). Monozygotic twins of different sex. Journal of Medical Genetics 3(2), 117-123. http://dx.doi.org/10.1136/jmg.3.2.117

Daily Mail reporetr, (2012). Identical twins ARE genetically different as study shows their DNA changes in the womb explaining why some are more prone to disease than others. [Online] Available:

http://www.dailymail.co.uk/sciencetech/article-2232148/Identical-twins-genetically-differentresearch-suggests.htm

( September 10, 2014).

Steinman, G., (2006) Mechanisms of Twinning: VII. Effect of Diet and Heredity on the Human Twinning Rate. The journal of Reproductive Medicine. 51(5), 405-410.

Oxford Health Review, (2014). Fact about multiple pregnancies. [Online] Available: http://oxfordhealth.info/Reproduction-and-genetics.php ( September 17, 2014)

Tran, U. S., Stieger, S., \& Voracek, M. (2014) Latent variable analysis indicates that seasonal anisotropy accounts for the higher prevalence of left-handedness in men. Cortex. 57, 188-197. http://dx.doi.org/10.1016/j.cortex.2014.04.011

Papadatou-Pastou, M., Martin, M., Munafò, MR., \& Jones, GV. (2008) Sex differences in left-handedness: a meta-analysis of 144 studies. Psychol Bull. 134(5), 677-699. http://dx.doi.org/10.1037/a0012814 


\section{MlMacrothink}

Journal of Biology and Life Science ISSN 2157-6076 2015, Vol. 6, No. 1

Vuoksimaa, E., Koskenvuo, M., Rose, R. J., \& Kaprio, J. (2009) Origins of handedness: a nationwide study of 30,161 adults. Neuropsychologia. 47(5), 1294-1301. http://dx.doi.org/10.1016/j.neuropsychologia.2009.01.007

Gilbert, AN., \& Wysocki CJ. (1992) Hand preference and age in the United States. Neuropsychologia. 30(7), 601-608. http://dx.doi.org/10.1016/0028-3932(92)90065-T

Peters, M., Reimers, S., \& Manning, J. T. (2006) Hand preference for writing and associations with selected demographic and behavioral variables in 255,100 subjects: the BBC internet study. Brain Cogn. 62(2), 177-189. http://dx.doi.org/10.1016/j.bandc.2006.04.005

Ocklenburg, S., Christian Beste, C., \& Güntürkün, O. ( 2013) Handedness: A neurogenetic shift of perspective. Neuroscience and Biobehavioral Reviews. 37, 2788-2793. http://dx.doi.org/10.1016/j.neubiorev.2013.09.014

Reiss, M., \& Reiss, G. (1999) Earedness and handedness: distribution in a German sample with some family data. Cortex. 35(3), 403-412. http://dx.doi.org/10.1016/S0010-9452(08)70808-6

Vuoksimaa, E., Eriksson, C. J. P., Pulkkinen, L., Rose, R. J., \& Kaprio, J. (2010). Decreased prevalence of left-handedness among females with male co-twins: Evidence suggesting prenatal testosterone transfer in humans?. Psychoneuroendocrinology. 35, 1462-1472. http://dx.doi.org/10.1016/j.psyneuen.2010.04.013

Orlebeke, J. F., Knol, D. L., Koopmans, J. R., Boomsma, D. I., \& Bleker, O. P. (1996) left-handedness in twins; genes or environment?. Cortex. 32, 479-490. http://dx.doi.org/10.1016/S0010-9452(96)80005-0

Davis, A., \& Annett, M. (1994) Handedness as a function of twinning, age and sex. Cortex. 30(1), 105-111. http://dx.doi.org/10.1016/S0010-9452(13)80326-7

Annett, M. (1978) A single gene explanation of right and left handedness and brainedness. Coventry : Lanchester Polytechnic.

Annett, M. (1985) Left, Right, Hand and Brain: The Right Shift Theory. London: Lawrence Erlbaum., 271.

Medland, S. E., Wright, M. J., Geffen, G. M., Hay, D. A., Levy, F., Martin, N. G., \& Duffy, D. L. (2003). Special twin environments, genetic influences and their effects on the handedness of twins and their siblings. Twin Research: The Official Journal of the International Society for Twin Studies, 6(2), 119-130. http://dx.doi.org/10.1375/136905203321536245

Francks, C., Fisher, S. E., MacPhie, I. L., Richardson, A. J., Marlow, A. J., Stein, J. F., Monaco, A. P. (2002). A genomewide linkage screen for relative hand skill in sibling pairs. American Journal of Human Genetics, 70(3), 800-805. http://dx.doi.org/10.1086/339249

Francks, C., Maegawa, S., Lauren, J., Abrahams, B. S., Velayos-Baeza, A., Medland, S. E., Colella, S., Groszer, M., McAuley, E. Z., Caffrey, T. M., Timmusk, T., Pruunsild, P., Koppel, I., Lind, P. A., Matsumoto-Itaba, N., Nicod, J., Xiong, L., Joober, R., Enard, W., Krinsky, B., Nanba, E., Richardson, A. J., Riley, B. P., Martin, N. G., Strittmatter, S. M., Möller, H. J., 


\section{Macrothink}

Rujescu, D., St Clair, D., Muglia, P., Roos, J. L., Fisher, S. E., Wade-Martins, R., Rouleau, G. A., Stein, J. F., Karayiorgou, M., Geschwind, D. H., Ragoussis, J., Kendler, K. S., Airaksinen, M. S., Oshimura, M., DeLisi, L. E., Monaco, A. P. (2007). LRRTM1 on chromosome 2p12 is a maternally suppressed gene that is associated paternally with handedness and schizophrenia. Molecular Psychiatry, 12, 1129-1139, 1057.

Medland, S. E., Duffy, D. L., Spurdle, A. B., Wright, M. J., Geffen, G. M., Montgomery, G.W., Martin, N. G. (2005). Opposite effects of androgen receptor CAG repeat length on increased risk of left-handedness in males and females. Behavior Genetics, 35(6), 735-744. http://dx.doi.org/10.1007/s10519-005-6187-3

Warren, D. M., Stern, M., Duggirala, R., Dyer, T. D., \& Almasy, L. (2006). Heritability and linkage analysis of hand, foot, and eye preference in Mexican Americans. Laterality, 11(6), 508-524. http://dx.doi.org/10.1080/13576500600761056

Van Agtmael, T., Forrest, S. M., \& Williamson, R. (2002). Parametric and nonparametric linkage analysis of several candidate regions for genes for human handedness. European Journal of Human Genetics: EJHG, 10(10), 623-630. http://dx.doi.org/10.1038/sj.ejhg.5200851

Goble, D. J., \& Brown, S. H. (2008). The biological and behavioral basis of upper limb asymmetries in sensorimotor performance. Neuroscience and Biobehavioral Reviews, 32(3), 598-610. http://dx.doi.org/10.1016/j.neubiorev.2007.10.006

\section{Copyright Disclaimer}

Copyright for this article is retained by the author(s), with first publication rights granted to the journal.

This is an open-access article distributed under the terms and conditions of the Creative Commons Attribution license (http://creativecommons.org/licenses/by/3.0/). 